been used to employ 7700 therapists ( 26 per primary care trust in England) providing 1.54 million treatment courses of six sessions each a year. This estimate increases to 2.43 million if the therapy is delivered by a graduate mental health worker and falls to 0.51 million if the course of treatment is lengthened to 18 sessions.

\section{Comment}

Resources associated with higher levels of NHS antidepressant prescribing in England in 2002 compared with 1991 could have been used to deliver cognitive behaviour therapy to 1.54 million patients, more than a third of adults with depression or mixed anxiety depression. ${ }^{4}$ The recent rise in antidepressant prescribing is likely to be due to increased awareness of depression by patients and professionals; reduced side effects associated with newer antidepressants; and the broadening range of indications for which antidepressants are prescribed (for example, panic disorder, seasonal affective disorder, premenstrual syndrome). Despite concern about the dangers of antidepressants, ${ }^{1}$ evidence of ineffective and inefficient prescribing, ${ }^{5}$ and the effectiveness of alternative treatments, ${ }^{2}$ drugs are overwhelmingly the mainstay of treatment for depression in general practice. Increases in the pharmacological treatment of depression have not been matched by the development of psychological services of proved effectiveness, which may reflect the absence of a powerful body, equivalent to the pharmaceutical industry, to promote their development and use.

Although cognitive behaviour therapy is relatively expensive and its population cost effectiveness has not been shown, other cheaper alternatives to both antidepressants and psychotherapy-for example, self help and exercise-may be of equal benefit to patients with mild to moderate depression. ${ }^{2}$ Our analysis takes no account of the training costs of psychotherapists but we have also ignored the cumulative cost of drugs incurred in the 11 years. Despite these limitations, the analysis highlights the scale of resources expended in this area and the uncertainty around alternative

\section{What is already known on this topic}

The prescribing of antidepressant drugs has risen substantially in the United Kingdom since the early 1990 s

Cognitive behaviour therapy is an effective alternative to antidepressant drugs

\section{What this study adds}

Opportunity costs indicate that development of psychological therapies is a feasible alternative to antidepressants

treatment for particular groups of patients; the results indicate that there is a clear need for further research to establish the most appropriate balance between drugs and non-pharmacological treatments for depression.

We thank Steve Pilling and Glyn Lewis for helpful comments and suggestions about an earlier draft of this paper.

Contributors: DG had the idea. SH did the analysis and drafted the paper. All authors contributed to the interpretation of the results and the editing of the paper. SH and DG are guarantors. Funding: None.

Competing interests: DG is a member of the Medicines and Healthcare Products Regulatory Agency expert working group on the safety of selective serotonin reuptake inhibitors. He acts as an independent adviser, receiving travel expenses and a small fee for meeting attendance and reading materials in preparation for the meeting.

Ethical approval: Not needed.

1 Gunnell D, Ashby D. Antidepressants and suicide: what is the balance of benefit and risk? $B M J$ 2004:329:34-8.

National Institute for Clinical Excellence. Management of depression in primary and secondary care. London: NICE, 2004. www.nice.org.uk/ CG023NICEguideline (accessed $28 \mathrm{Feb} 2005$ ).

3 Netten A, Curtis L. Unit costs of health and social care 2003. Canterbury: Personal Social Services Research Unit, University of Kent, 2003.

4 Office for National Statistics. Psychiatric morbidity among adults living in private households, 2000. London: Stationery Office, 2001.

Lawrenson RA, Tyrer F, Newson RB, Farmer RDT. The treatment of depression in UK general practice: selective serotonin reuptake inhibitors and tricyclic antidepressants compared. J Affective Disord 2000;59:149-57

(Accepted 10 January 2005)

doi 10.1136/bmj.38377.715799.F7

\title{
National survey of UK emergency endoscopy units
}

\author{
Andrew Douglass, Michael G Bramble, Ian Barrison
}

\begin{abstract}
Friarage Hospital, Northallerton DL6 1JG

Andrew Douglass consultant gastroenterologist

The James Cook University Hospital, Middlesbrough TS4 3BW

Michael G Bramble consultant gastroenterologist continued over

Upper gastrointestinal bleeding is a common cause of hospital admission and is accompanied by considerable mortality. For patients to survive, the timing of endoscopy can be critical. Clinical scoring systems identify high risk patients who need prompt endoscopy after appropriate resuscitation. ${ }^{1}$ Early endoscopic intervention to prevent rebleeding is effective in high risk patients. ${ }^{2} \mathrm{~A}$ recent report indicated that patients are still dying as a consequence of delayed endoscopy, ${ }^{3}$ but no data exist on the provision of emergency endoscopy services in the United Kingdom. As part of a national census of endoscopy training units, we examined the extent of out of hours endoscopy provision, including volume of work and resources used.
\end{abstract}

\section{Participants, methods, and results}

We approached endoscopy units registered with the UK Joint Advisory Group. We developed a questionnaire from the British Society of Gastroenterology working party report, ${ }^{4}$ and distributed it to lead clinicians in 2002. We sent two reminders to centres that failed to reply. We finished collecting data by August 2002. The number of endoscopy rooms was a surrogate marker for the size of the unit. The response rate was $77 \%$ ( 150 centres).

This article was posted on bmj.com on 11 March 2005: http://bmj.com/ cgi/doi/10.1136/bmj.38379.662616.F7 
UK units with emergency endoscopy facilities: consultant numbers, volume of endoscopies, and location and staffing for out of hours endoscopies

\begin{tabular}{|c|c|c|c|c|c|c|c|c|c|}
\hline \multirow{3}{*}{$\begin{array}{l}\text { No of } \\
\text { endoscopy } \\
\text { rooms }\end{array}$} & \multirow{3}{*}{$\begin{array}{l}\text { No of } \\
\text { units }\end{array}$} & \multirow{3}{*}{$\begin{array}{l}\text { Median No of } \\
\text { consultants on } \\
\text { rota }\end{array}$} & \multirow{3}{*}{$\begin{array}{c}\text { Mean No of upper } \\
\text { gastrointestinal bleeding } \\
\text { cases per } 100000 \text { per } \\
\text { year (95\% confidence } \\
\text { interval) }\end{array}$} & \multicolumn{6}{|c|}{ Out of hours endoscopies } \\
\hline & & & & \multicolumn{3}{|c|}{ Location } & \multicolumn{3}{|c|}{ Nursing staff } \\
\hline & & & & Theatre & Endoscopy & Ward & Theatre & Endoscopy & Ward \\
\hline 1 & 11 & 4 & 106 (24.1 to 187.8$)$ & $4 / 10$ & $6 / 10$ & 0 & $4 / 10$ & $5 / 10$ & $1 / 10$ \\
\hline 2 & 66 & 5 & 72.9 (55.9 to 90.0$)$ & $29 / 65$ & $31 / 65$ & $4 / 65$ & $33 / 66$ & $28 / 66$ & $5 / 66$ \\
\hline 3 & 25 & 4 & 115 (55.3 to 176.6) & $7 / 24$ & $14 / 24$ & $2 / 24$ & $8 / 23$ & $11 / 23$ & $2 / 23$ \\
\hline$\geq 4$ & 13 & 5.5 & 123 (49.3 to 196.7) & $2 / 13$ & $10 / 13$ & $1 / 13$ & 523 & $5 / 12$ & $2 / 12$ \\
\hline
\end{tabular}

Hemel Hempstead General Hospital, Hertfordshire HP2 4AD

Ian Barrison consultant gastroenterologist Correspondence to: M G Bramble lmike.bramble@ stees.nhs.uk
Overall, 35 of the 150 units that responded (23\%) did not provide an emergency out of hours endoscopy service. In the $115(77 \%)$ units that did, this was provided by a median of five consultants and featured junior endoscopists in 47 units, acting independently in 15. Forty one units reported having an ad hoc or goodwill rota rather than a formal on-call arrangement. Out of hours procedures were done in the endoscopy department in 61 units, in theatre in 43 units, and on the ward for the remainder. Trained endoscopy staff helped the endoscopist in 49 units. Theatre staff support was needed in 47 units and ward staff in 15 units. Larger units tended to do the endoscopies in the endoscopy department, but there was no variation in location or staffing for units of smaller sizes (table). A mean of 90.2 (95\% confidence interval 72.0 to 108.5) emergency endoscopies per 100000 population were done each year for upper gastrointestinal bleeding, of which 26.7 were out of hours. Although larger units (including tertiary centres) received more patients with gastrointestinal bleeding and did more out of hours procedures this was not significant.

\section{Comment}

Hospitals that admit patients with acute upper gastrointestinal haemorrhage lack emergency endoscopy provision; hospitals need to manage about 100 patients per 100000 population with acute upper gastrointestinal haemorrhage. ${ }^{1}$ Mortality from upper gastrointestinal bleeding remains high at 14\%, and this has been attributed to the ageing population. ${ }^{1}$ Our survey indicates, however, that in many hospitals patients might be dying because of a lack of an

\section{What is already known on this topic}

Risk of death after upper gastrointestinal haemorrhage is related to the rebleeding rate and has not decreased despite modern endoscopic methods of stopping haemorrhage in high risk patients

Endoscopy was done too late in $79 \%$ of cases in which the patient died

\section{What this study adds}

Half of all hospitals have no emergency on-call rota for patients with acute upper gastrointestinal haemorrhage, and, often, emergency gastroscopy was in unfamiliar surroundings helped by staff unfamiliar with endoscopy appropriately timed endoscopy, which would identify high risk patients and offer the possibility of endoscopic therapeutic intervention.

Emergency endoscopies in high risk patients were often done in unfamiliar surroundings, with staff not used to dealing with such patients, conflicting with guidance issued by the British Society of Gastroenterology. ${ }^{4}$ Mortality in hospitals with a dedicated bleeding unit is almost half the national average, ${ }^{5}$ indicating that at least $40 \%$ of the deaths associated with gastrointestinal bleeding are preventable. We believe that one reason for this is the failure of many units to ensure that out of hours emergency rotas exist for such patients. Smaller units should consider combining with larger ones to provide cross cover and rectify a shortfall in the service that is essentially manpower related. Physicians and surgeons should work together in this important area so that 24 hour cover can be provided by a hospital equipped to deal with all aspects of serious gastrointestinal haemorrhage.

Contributors: MGB and IB conceived the study. The questionnaire, data collection, and analysis were done by $\mathrm{AD}$. All authors wrote the paper. $\mathrm{AD}$ is guarantor.

Funding: None.

Competing interests: None declared.

Ethical approval: British Society of Gastroenterology Endoscopy Committee.

1 Rockall TA, Logan RF, Devlin HB, Northfield TC. Risk assessment after acute upper gastrointestinal haemorrhage. Gut 1996;38:316-21.

2 Cook DJ, Gayatt GH, Salena BJ, Laine LA. Endoscopic therapy for acute non variceal haemorrhage: a meta analysis. Gastroenterology 1992;102: $139-48$.

3 National Confidential Enquiry into Patient Outcome and Death. Scoping our practice: the 2004 report of the National Confidential Enquiry into Patient Outcome and Death. London: NCEPOD, 2004.

4 British Society of Gastroenterology Working Party. Provision of endoscopy related services in district general hospitals. London: BSG, 2001.

Sanders DS, Perry MJ, Jones SGW, McFarlane E, Johnson AG, Gleeson DC, et al. Effectivenes of an upper gastrointestinal haemorrhage unit: a pC, et a E prospective an 94.

(Accepted 18 January 2005)

doi 10.1136/bmj.38379.662616.F7

\section{Endpiece}

\section{Overtreatment?}

I was languishing, but you, Symmachus, came to me At once, accompanied by a hundred medical students.

A hundred hands, frozen by the north wind, touched me;

I didn't have a fever, Symmachus, now I do. Martial, Roman poet

S L Baldeweg, A level student, London 